\title{
Cognitive Effects of Systemic Therapy in Patients with Breast Cancer
}

\author{
Ute Berndt $^{\mathrm{a}}$ Bernd Leplow ${ }^{\mathrm{b}}$ Eva Kantelhardt ${ }^{\mathrm{a}}$ Christoph Thomssen ${ }^{\mathrm{a}}$ \\ ${ }^{a}$ Klinik und Poliklinik für Gynäkologie, \\ ${ }^{\mathrm{b}}$ Institut für Psychologie der Martin-Luther-Universität Halle-Wittenberg, Germany
}

\section{Key Words}

Breast cancer - Cognitive side effects · Chemotherapy . Endocrine therapy

\section{Summary}

Many patients with breast cancer complain about concentration and memory problems in connection with systemic therapy. A number of studies investigating the possible decrease in cognitive abilities were published in the 1980s. Numerous studies showed impaired performance of patients receiving chemotherapy. The results concerning profile, extent, and duration of cognitive impairments are, however, non-uniform. Increasing interest has been focused in the last years on effects of endocrine therapy on cognitive capacity - especially concerning the effects of the almost complete estrogen depletion caused by aromatase inhibitors. Often, the published studies did not evaluate particular effects of endocrine therapy without considering interference of cytotoxic treatment. Furthermore, the different endocrine medications (antiestrogens vs. aromatase inhibitors) were usually not regarded separately despite different mechanisms of action. Hence, the results of past investigations are also controversial. In the future, prospective trials with larger samples are necessary. Differentiation between chemotherapy and endocrine therapy is essential. Likewise, different types of endocrine therapy should be examined separately.

\author{
Schlüsselwörter \\ Mammakarzinom - Kognitive Nebenwirkungen · \\ Chemotherapie $\cdot$ Endokrine Therapie
}

\section{Zusammenfassung}

Vor dem Hintergrund von Patientinnenklagen über Konzentrations- und Gedächtnisprobleme im Zusammenhang mit der systemischen Therapie des Mammakarzinoms sind seit den 1980er Jahren eine Reihe von Studien zur Untersuchung einer möglichen Abnahme kognitiver Fähigkeiten erschienen. Bei Patientinnen, die eine Behandlung mit Zytostatika erhalten hatten, zeigten sich in zahlreichen Studien Leistungsminderungen. Die Ergebnisse sind jedoch in Bezug auf Profil, Ausmaß und Dauer der kognitiven Beeinträchtigungen uneinheitlich. In den letzten Jahren ist ein zunehmendes Forschungsinteresse an den Auswirkungen der endokrinen Therapie auf die kognitive Leistungsfähigkeit der Patientinnen zu verzeichnen, insbesondere daran, inwieweit eine durch die Aromatasehemmertherapie hervorgerufene, nahezu vollständige Östrogendeprivation kognitive Fähigkeiten beeinflusst. In vielen der bisher publizierten Untersuchungen wurden die Auswirkungen der endokrinen Therapie nicht isoliert von der zytostatischen Behandlung untersucht, die jedoch als Störfaktor zu werten ist. Zudem wurden die verschiedenen endokrinen Medikationen (Antiöstrogene vs. Aromatasehemmer) trotz unterschiedlicher Wirkungsweise meist nicht separat voneinander betrachtet. Die Ergebnisse der bisherigen Untersuchungen sind auch hier uneinheitlich. Künftig sind prospektive Studien mit größeren Stichproben sowie eine Trennung von Chemotherapie und endokrinen Therapieformen erforderlich. Letztere sollten ebenfalls separat von einander untersucht werden.

\section{KARGER}

Fax +497614520714

Information@Karger.de

www.karger.com (c) 2009 S. Karger GmbH, Freiburg

Accessible online at:

www.karger.com/brc 


\section{Introduction}

It is remarkable that numerous patients with breast cancer report about memory and concentration problems. Against this background, in the 1980s, potential factors influencing mental performance were evaluated in connection with systemic cancer therapy. First, the main point of research lay on cognitive effects caused by chemotherapy, but increasing interest has been focused on the effects of endocrine therapy for some time.

\section{Cognitive Effects of Chemotherapy for Breast Cancer}

\section{Imaging Procedures and Psychological Investigation}

The majority of psychological tests investigating the topic of cognition and chemotherapy show a connection between chemotherapy and reduced performance [1-12]. By means of imaging procedures, morphologic and metabolic changes in the brain of female patients who were on chemotherapy compared with a healthy control group were proven. Results showed a decrease in grey brain substance [13] on the one hand, and a reduction in metabolic activity in the Gyrus precentalis and Broca's language center [14] on the other hand. Schagen et al. [15] observed asymmetries in the alpha rhythm $\leq 0.5 \mathrm{~Hz}$ approximately 2 years after chemotherapy, with patients having received high-dose chemotherapy particularly affected. Also, Silvermann et al. [16] used positron emission tomography (PET) imaging to show that breast cancer patients while dealing with memory tasks had a significant decrease in cerebral blood flow in some regions of the frontal cortex and the cerebellum 5-10 years after they had received chemotherapy. Patients who had additionally received tamoxifen showed a reduction in basal ganglia metabolism compared with patients who exclusively received chemotherapy and the untreated control group. Further side effects of chemotherapy, e.g. anemia [17], are likewise associated with increased concentration and memory problems as well as a decreased control function concerning planning and acting [18].

The majority of the test-psychological investigations on the topic of 'cognition and chemotherapy' when treating breast cancer shows impairment in comparison with the control group $[1,7-9,11]$. Still, the exact connection between chemotherapy and cognitive efficiency is not fully clarified. The measured loss of performance varies strongly between the different investigations, with incidences from $16 \%$ [19] up to $75 \%$ [7]. The profile of the neuropsychological deficits differs as well. The question of a cognitive long-term impairment is under discussion. Schagen et al. [20] report about almost complete recovery of the cognitive deficits whereas Ahles et al. [11] still see impairments 10 years after chemotherapy.

\section{Further Influencing Factors}

Other influencing factors are being increasingly discussed as reasons for cognitive impairment, such as changes in the hormonal environment due to therapy-induced menopause, termination of hormone replacement therapy, or endocrine therapy. Increasing evidence consolidates that emotional distress is also involved in causing impaired cognitive achievement [1, 21-23]. Also, side effects like fatigue and reduced quality of life, as well as additional medication (e.g. steroids, analgesics) could reduce cognitive levels [24].

\section{Meta-Analyses and Reviews}

Some authors compiled meta-analyses on studies examining cognitive effects of cytostatic therapy. Stewart et al. [25] analyzed 7 studies, and determined a slight but significant impairment of general cognitive efficiency; however, the results were not clinically relevant. Also, Mores et al. [4] stated in a review that cognitive impairments were statistically significant, but the effects were small and probably insignificant for everyday life. They emphasized the importance of always publishing the level of the effect. Falleti et al. [26] reviewed 5 cross-sectional studies and 1 longitudinal study. The results showed that women who received adjuvant chemotherapy for breast cancer were also cognitively impaired. It was demonstrated that deficits were larger the shorter the period since the last chemotherapy. The extent of measured impairment seemed, however, to be connected with the individual study design. Jansen et al. [27] analyzed 16 studies which dealt with cognitive effects of chemotherapy. They concluded that in all studies significant impairments regarding visual memory were seen independent of the selected control group. However, when comparing neuropsychological test data with standard test values, significant differences also showed up in areas of control function for planning and acting, speed of data processing, as well as verbal and visual memory.

\section{Prospective Studies}

It is remarkable that in recent prospective investigations no or only a small decrease in capacity was determined. The 3-year prospective study by Jenkins et al. [28], in which cognitive impairments were examined particularly in patients with breast cancer, showed no significant differences between the individual groups (patients with chemotherapy vs. patients with endocrine therapy vs. healthy control group). Patients with chemotherapy-induced menopause revealed non-significant impairment. Except for some patients who showed restrictions regarding concentration and memory, the majority was either unimpaired or even improved their performance over time. A further prospective study by Hermelink et al. [22] on pa- 
Table. 1. Reasons for limited comparability of individual study results

- Study design: cross-sectional investigations vs. longitudinal studies
- Small samples
- Differences
. Type of chemotherapy
. Duration of treatment
. Consideration of endocrine aspects
. Selection of cognitive function tests
. Time points of census
. Selection of control groups
. Consideration of other medication
. Application of statistical procedures
. Secondary diagnosis

tients with breast cancer found average values below standard even before neoadjuvant chemotherapy. After chemotherapy, however, only part of the patients $(27 \%)$ showed decreased results, the majority showed no change $(45 \%)$, and a small group even improved their performance $(28 \%)$.

\section{Interpretation of Findings}

Reasons for rather heterogeneous results probably lie in the variety of study designs (table 1). Most studies were launched as cross-sectional investigations, and cognitive achievements were rarely evaluated before systemic treatment. Therefore, patients who exhibit average cognitive values after chemotherapy can yet be impaired since an above average level could have been possible before treatment. However, even in longitudinal investigations, it cannot be excluded that cognitive impairments due to diagnostic shock or surgical procedures were already present and could have improved until the second census. Since participation in cognition tests is voluntary, samples are self-selected, i.e. rather intelligent and motivated patients admit themselves to test-psychological investigation. Most investigations have small samples. In addition, the test ranges of cognitive abilities are not standardized, and the assigned chemotherapy and time of census differ between each publication. Emotional distress as influencing factor was partly neglected. The selection of the control groups differed substantially. Additional medication apart from chemotherapy was often insufficiently documented. Changes in the hormonal situation by chemotherapy-induced menopause or adjuvant endocrine therapy were not always considered. Ultimately, different methods of data analysis showed diverse results [24]. Generally, it was also neglected that chemotherapy patients almost completely withdraw from social and vocational life and thus have less mental input than vocationally active healthy subjects. Mental performance can be reduced, however, also due to lack of training. It is shown that people who mentally stimulate themselves even in older age have a smaller risk of developing dementia [29]. Also, physical activities contribute to preservation of mental health [30]. Most extensive agreement exists on the fact that patients exposed to high-dose chemotherapy or numerous chemotherapy cycles show impairment more often $[7,8,11]$. Self-reported cognitive restrictions in most investigations do not correlate with the objective test data but with fear and depression.

In accordance with the majority of authors, prospective investigations with larger samples and better analysis of other influential factors are required including a detailed collection of baseline data before use of systemic treatment. In the treatment of breast cancer, individual substances might have different effects on mental activity. In a longitudinal investigation, Bender et al. [31] determined impaired verbal memory in those patients who received chemotherapy. Patients who were additionally treated with tamoxifen showed a reduction in both visual and verbal memory. Silverman et al. [16] determined significantly reduced metabolism in the basal ganglia in patients who had been treated with tamoxifen besides chemotherapy. Treatment of hormone receptor-positive postmenopausal breast cancer has shifted from the selective estrogen receptor modulator tamoxifen to third generation aromatase inhibitors. The question arises to what extent treatment with aromatase inhibitors, which results in almost complete suppression of estrogen levels, might affect cerebral function. Some form of influence seems inevitable since estrogen receptors were demonstrated in the brain [16].

\section{Cognitive Effects of Endocrine Therapy}

\section{Estrogen and the Brain}

Estrogen receptors are found in the hypothalamus, the pituitary gland, the cerebral cortex, the central brain, and the brain stem [32]. Estrogen receptors are also present in the hippocampus, the essential structure for cognitive processes such as learning and memory, emotions, and the rapid eye movement (REM) sleep [33, 34]. Different neuro- and psychoprotective effects of estrogens were found in the last years. Several studies showed that estrogens can affect the morphology of the hippocampus [35-37] by promoting synapse formation and density of synaptic branching in the hippocampus and strengthening the hippocampal long-term potentiation [38]. Animal experiments proved that estrogens promote formation of new dendritic thorns on hippocampal CA1 pyramid cells [39]. Estrogens also affect different neurotransmitter systems in the brain, like the dopaminergic, serotonergic, glutamergic, noradrenergic, and cholinergic systems [40]. The hormone $17 \beta$-estradiol also protects neurons by exerting an antioxidative effect against oxidative stress [41]. Finally, protective effects of estrogen contribute to reducing the risk of developing Alzheimer's disease [33] or schizophrenia [42]. Positive estrogen effects could also be found in patients with Parkinson's disease [43] and in connection with reduced susceptibility for convulsions [44]. Increased release after brain 
injury also points towards a neuroprotective function of estrogens [34]. Estrogens, however, also affect brain function by improving cerebral blood flow [45] and optimizing glucose uptake in the brain [46]. High estrogen doses act antidepressive and reverse effects of antidepressants in animal experiments. Moreover, estrogen influence was determined for short-term memory, fine motor skills, and spatial orientation in healthy women [43]. Several authors found protective or achievement-increasing effects of estrogen and/or estrogen and progesterone replacement in postmenopausal women $[47,48]$. In a randomized placebo-controlled investigation on postmenopausal women (Women's Health Initiative Memory Study), however, no advantage could be measured regarding cognitive achievements in patients with hormone replacement in comparison to the placebo group, even though there were more women with lag of cognitive function. The contradictory findings of the individual studies may be explained by the role of the start of hormone therapy with regard to the patient's age. Much evidence is given that positive effects of hormone replacement therapy are present if therapy begins immediately after menopause. In later years, damage may even occur since brain aging has progressed by the time hormone replacement is started [49].

Imaging Procedures, Neurophysiological and Psychological Investigation

Considering the almost complete inhibition of estrogen synthesis by treatment with aromatase inhibitors, decreased synapse density and fewer synapse-relevant proteins are expected. Effects on the excitation transmission of the synapses in the hippocampus are probable; this might result in cognitive performance lags. In contrast to the influence of estrogens on neurophysiological actions, current research hardly supplies conclusive results on the topic of cognitive changes by endocrine therapy of breast cancer. Studies on cognitive effects of tamoxifen are rare and have non-uniform results. It was shown in animal experiments that tamoxifen can lead to impairment of learning and memory in mice [40].

Eberling et al. [37] examined effects of estrogen and tamoxifen by means of PET and magnetic resonance imaging (MRI). Patients on tamoxifen were compared with patients on estrogens and also a control group without medication. Women under tamoxifen showed a decreased metabolism in expanded areas of the inferior and dorso-lateral front lobe as well as significantly weaker performance regarding semantic memory compared with the 2 other groups. The right and left volume of the hippocampus was significantly smaller than that of the estrogen group. The untreated group achieved results between the tamoxifen and the estrogen group. In a pilot study, Jenkins et al. [50] evaluated breast cancer patients in order to examine whether endocrine therapy (ATAC design: arimidex-tamoxifen alone or in combination) has an effect on cognition. The results point to the fact that not all cognitive ability is affected. Significant differences were determined compared to the control group regarding verbal memory, particularly the immediate recall and information-processing speed. The length of the endocrine therapy did not correlate with the occurrence of cognitive impairments. Comparison between the treatment arms (aromatase inhibitors vs. tamoxifen) was not intended. But since aromatase inhibitors act differently from antiestrogens, diverse and possibly opposite effects could be expected.

Bender et al. [51] examined patients with breast cancer on tamoxifen or anastrozole for at least 3 months duration. Patients on aromatase inhibitors showed weaker performance in visual and verbal learning compared to the tamoxifen group. In an investigation by Palmer et al. [52], premenopausal patients on tamoxifen with an average treatment duration of 2.3 years were compared with a healthy control group. None of the subjects had received chemotherapy. Patients on tamoxifen were compromised compared to healthy subjects regarding visual and verbal memory, verbal fluency, ability of spatial orientation, and information processing speed. Also, Collins et al. [53] determined a decrease in mental efficiency in breast cancer patients on endocrine therapy. In a longitudinal study, they examined patients on tamoxifen vs. anastrozole vs. a healthy control group. The results of a neuropsychological test battery were compared at the beginning of therapy and 5-6 months later. The achievements of the 2 endocrine groups between the 2 time points in comparison with the healthy control group were weaker. In comparison to the healthy control group, the group on aromatase inhibitors had a 9-fold risk of decreased cognitive results, the tamoxifen group, however, only a 5-fold risk. Additionally, the group on anastrozole ( small sample $n=14$ !) showed weak results in nearly all fields. Endocrine-treated patients were impaired especially concerning information-processing speed and verbal memory.

Ernst et al. [54] report a decrease in the cerebral marker myo-inositol (MI) in patients on tamoxifen. A higher concentration of $\mathrm{MI}$ is associated with poor memory functions, and MI levels decrease with age [55]. The patients examined by Ernst et al. [54] received tamoxifen or hormone replacement therapy or neither. Both tamoxifen groups and the hormone replacement group showed clearly reduced concentrations of $\mathrm{MI}$ in all brain regions in comparison to the control group. Increased duration of tamoxifen therapy led to a greater benefit for the patients. This suggests that tamoxifen treatment could have protective effects by exerting a partially intrinsic effect on memory function. It remains unclear to what extent these results are transferable to younger patients.

The investigation by Paganini, Hill, and Clark [56] found no significant difference between the cognitive achievements over time in patients taking tamoxifen and those who did not take the medication. Substantial methodical deficits during data capture should be noted. Also, Schagen et al. [9] and 
Ahles et al. [11] revealed no significant differences between patients with and without tamoxifen treatment. Similar results were found by Hermelink et al. [57]. Their prospective investigations on patients before and after adjuvant chemotherapy to investigate the effects of endocrine therapy were supplemented with another census. The results of the third testing 1 year after the first data acquisition did not show significant differences comparing treated patients with those who did not receive therapy. Also, the comparison between the tamoxifen and the aromatase inhibitor group did not show significant differences. However, the duration of endocrine therapy was rather short and the sample size of aromatase inhibitor patients very small $(\mathrm{n}=13)$. Jenkins et al. [58] came to similar conclusions [58]. They launched a subprotocoll in the context of the IBIS II trial (double-blind randomized prevention study for the investigation of the preventive effect of anastrozole vs. placebo for postmenopausal risk patients) to measure the effects of anastrozole on mental performance. The assessment took place before randomization, after 6 and after 24 months. No significant differences were determined between the anastrozole group and patients on placebo. However, only $67 \%$ of the patients reached the third time point of evaluation since due to side effects numerous patients dropped out of the study prematurely, which may have caused an underestimation of the effects. It is also not clear whether long-term use of anastrozole $>24$ months leads to a reduction in cognitive performance. Besides, it is well known that compliance for endocrine therapy is reduced in patients with breast cancer. Since patients with disease deal less carefully with medical advice, the question arises whether this does not all the more apply to healthy test persons (e.g. prevention IBIS II trial).

\section{Interpretation of Findings}

On the one hand, evidence on the topic of antiestrogen therapy and cognition seems very heterogeneous, sometimes even contradictory. On the other hand, numerous references show that a change in estrogen levels can cause both anatomical and physiological changes in the central nervous system. It is essential to separate and compare the different endocrine therapies when investigating cognitive changes, since antiestrogens and aromatase inhibitors each have a specific and different mechanism of action. Also, patients treated with chemotherapy should be excluded since this therapy is to be considered as an interference factor. Similar to studies dealing with chemotherapy and cognition, it is difficult to find a suitable study design. Even with a longitudinal study design, diagnostic shock and surgery can affect cognition. Additionally, the extent of incompliance is not to be underestimated. Since patients take their medicines unobserved, there is no control of whether they adhere to the instructions. In some studies, non-compliance was examined in breast cancer patients on endocrine therapy. A questionnaire completed by 100 breast cancer patients to whom tamoxifen or an aromatase inhibitor was prescribed indicated that all patients obeyed the instructions. However, this was only verified for $80 \%$ of patients on tamoxifen and $66 \%$ of patients on aromatase inhibitors [59].

\section{Conclusions}

The effects of systemic therapy for breast cancer on cognitive performance have been evaluated by numerous studies. However, the data situation remains rather heterogeneous. The consequences of chemotherapy for the central nervous system are not clearly determined with regard to general incidence, extent of performance impairment, and affected functions. There are references that chemotherapy-induced menopause can also lead to cognitive impairment; this points to a decrease in mental performance caused by estrogen deficiency. Published data regarding endocrine therapy for breast cancer with antiestrogens or aromatase inhibitors is also contradictory. Individual studies differ, however, greatly in their setup. Prospective investigations with large sample size and a separation of chemotherapy and endocrine therapy are mandatory in the future. Different forms of endocrine therapy should be evaluated separately. Emotional distress should be considered as an influential factor. In such studies, it would be ideal to control the real intake of endocrine medication by laboratory tests in the context of the respective cognition studies.

\section{Conflict of Interest}

The authors indicated no potential conflicts of interest.

\section{References}

1 Wefel JS, Lenzi R, Theriault R, Buzdar AU, Cruickshank S, Meyers: 'Chemobrain' in breast carcinoma?: a prologue. Cancer 2004;101:466-75.

$\checkmark 2$ Tannock IF, Ahles TA, Ganz PA, van Dam FS: Cognitive impairment associated with chemotherapy for cancer: report of a workshop. J Clin Oncol 2004; 22:2233-9.

>3 Shilling V, Jenkins V, Morris R, Deutsch G, Bloomfield $\mathrm{D}$ : The effects of adjuvant chemotherapy on cognition in women with breast cancer - preliminary results of an observational longitudinal study. Breast 2005;14:142-50.
4 Morse R, Rodgers J, Verrill M, Kendell K: Neuropsychological functioning following systemic treatment in women treated for breast cancer: a review. Eur J Cancer 2003;39:2288-97.

5 Paraska C, Bender CM: Cognitive dysfunction following adjuvant chemotherapy for breast cancer: two case studies. Oncol Nurs Forum 2003;30:473-8.

6 Brezden CB, Phillips KA, Abdolell M, Bunston T, Tannock IF: Cognitive function in breast cancer patients receiving adjuvant chemotherapy. J Clin Oncol 2000;18:2695-701.
7 Wienecke M, Dienst ER: Neuropsychological assessment of cognitive functioning following chemotherapy for breast cancer. Psycho-Oncol 1995;4:61-6.

8 Van Dam FS, Schagen SB, Muller MJ, Boogerd W, vd Wall E, Droogleever Fortuyn ME, Rodenhuis S: Impairment of cognitive function in women receiving adjuvant treatment for high-risk breast cancer: high-dose versus standard-dose chemotherapy. J Natl Cancer Inst 1998;90:210-8. 
9 Schagen SB, van Dam FS, Muller MJ, Boogerd W, Lindeboom J, Bruning PF: Cognitive deficits after postoperative adjuvant chemotherapy for breast carcinoma. Cancer 1999;85:640-50.

10 Wefel JS, Lenzi R, Theriault RL, Davis RN, Meyers CA: The cognitive sequelae of standarddose adjuvant chemotherapy in women with breast carcinoma: results of a prospective, randomized, longitudinal trial. Cancer 2004;100:2292-9.

-11 Brezden CB, Phillips KA, Abdolell M, Bunston T, Tannock IF: Cognitive function in breast cancer patients receiving adjuvant chemotherapy. J Clin Oncol 2000;18:2695-1.

12 Ahles TA, Saykin AJ, Furstenberg CT, Cole B, Mott LA, Skalla K, Whedon MB, Bivens S, Mitchell T, Greenberg ER, Silberfarb PM: Neuropsychologic impact of standard-dose systemic chemotherapy in long-term survivors of breast cancer and lymphoma. J Clin Oncol 2002;20:485-93.

13 Saykin AJ, Ahles TA, Schoenfeld JD: Grey matter reduction on voxel-based morphometry in chemotherapy-treated cancer survivors. J Int Neuropsychol Soc 2003;9:246.

14 Silverman DH, Castellon SA, Abraham L, Dy CJ, Pio BS, Ganz PA: Abnormal regional brain metabolism in breast cancer survivors after adjuvant chemotherapy is associated with cognitive changes. Proc Am Soc Clin Oncol 2003;22:12.

15 Schagen SB, Hamburger HL, Muller MJ, Boogerd W, van Dam FS: Neurophysiological evaluation of late effects of adjuvant high-dose chemotherapy on cognitive function. J Neurooncol 2001;51:159-65.

16 Silvermann Dh, Dy CJ, Castellon SA Lai J, Pio BS, Abraham L, Waddell K, Petersen L, Phelps ME, Ganz PA: Altered frontocortical, cerebellar, and basal ganglia activity in adjuvant-treated breast cancer survivors 5-10 years after chemotherapy. Cancer Res Treat 2007;103:303-11.

17 Ludwig H, Strasser K: Symptomatology of anemia. Semin Oncol 2001;28:7-14.

18 Jacobsen PB, Thors CL, Cawley M, Ax E, Grendys EC: Relation of decline in haemoglobin to cognitive functioning and fatigue during chemotherapy treatment. Proc Am Soc Clin Oncol 2002;21:386.

$\checkmark 19$ Tchen N, Juffs HG, Downie FP, Yi QL, Hu H, Chemerynsky I, Clemons M, Crump M, Goss PE, Warr D, Tweedale ME, Tannock IF: Cognitive function, fatigue, and menopausal symptoms in women receiving adjuvant chemotherapy for breast cancer. J Clin Oncol 2003;15;21:4175-83.

20 Schagen SB, Muller MJ, Boogerd W, Rosenbrand RM, van Rhijn D, Rodenhuis S, van Dam F: Late effects of adjuvant chemotherapy on cognitive function: a follow-up study in breast cancer patients. Ann Oncol 2002;13:1387-97.

21 Troy L, McFarland K, Littman-Power S, Kelly BJ, Walpole ET, Wyld D, Thomson D: Cisplatin-based therapy: a neurological and neuropsychological review. Psychooncology 2000;9:29-39.

22 Hermelink K, Untch M, Lux MP, Kreienberg R, Beck T, Bauerfeind I, Münzel K: Cognitive function during neoadjuvant chemotherapy for breast cancer: results of a prospective, multicenter, longitudinal study. Cancer 2007;109:1905-1913.

23 Shilling V, Jenkins V: Self-reported cognitive problems in women receiving adjuvant therapy for breast cancer. Eur J Oncol Nurs 2007;11:6-15.

24 Shilling V, Jenkins V, Trapala I S: The misclassification of chemofog - methodological inconsistencies in the investigation of cognitive impairment after chemotherapy. Breast Cancer Res Treat 2006;27:1-5.
5 Stewart A, Bielajew C, Collins B, Parkinson M, Tomiak E: A meta-analysis of the neuropsychological effects of adjuvant chemotherapy treatment in women treated for breast cancer. Clin Neuropsychol 2006;20:76-89.

26 Falleti MG, Sanfilippo A, Maruff P, Weih L, Phillips KA: The nature and severity of cognitive impairment associated with adjuvant chemotherapy in women with breast cancer: a meta-analysis of the current literature. Brain Cogn 2005;59:60-70.

27 Jansen CE, Miaskowski C, Dodd M, Dowling G, Kramer G: A metaanalysis of studies of the effects of cancer chemotherapy on various domains of cognitive function. Cancer 2005;104:2222-33.

28 Jenkins V, Shilling V, Deutsch G, Bloomfield D, Morris R, et al.: A 3-year prospective study of the effects of adjuvant treatments on cognition in women with early stage breast cancer. Br J Cancer 2006;94:828-34.

29 Wilson RS, Mendes De Leon CF, Barnes LL, Schneider JA, Bienias JL, Evans DA, Bennett DA: Participation in cognitively stimulating activities and risk of incident Alzheimer disease. JAMA 2002;287:742-8.

30 Yaffe K, Barnes D, Nevitt M, Lui LY, Covinsky K: A prospective study of physical activity and cognitive decline in elderly women: women who walk. Arch Intern Med 2001;161:1703-8.

31 Bender CM, Sereika SM, Berga SL, Vogel VG, Brufsky AM, Paraska KK, Ryan CM: Cognitive impairment associated with adjuvant therapy in breast cancer. Psychooncology 2006;15:422-30.

32 Sherwin BB: Estrogen and cognitive functioning in women. Endocr Rev 2003;24:133-51 (review).

33 Behl C, Moosmann B: Neuroprotektive Aktivitäten von Estrogen. Nachr Chem 2001;49:332-6.

34 Wenderlein MJ: Aromatasehemmer riskant für das Gehirn? Geburtsh Frauenheilk 2005;65:144-8.

35 McEwen BS, Alves SE: Estrogen actions in the central nervous system. Endocr Rev 1999;20:279-307.

36 Foy MR: 17beta-estradiol: effect on CA1 hippocampal synaptic plasticity.. Neurobiol Learn Mem 2001;76:239-52 (review).

37 Eberling JL, Wu C, Tong-Turnbeaugh R, Jagust WJ: Estrogen- and tamoxifen-associated effects on brain structure and function. Neuroimage 2004; 21:364-71.

38 Shughrue PJ, Merchenthaler I: Estrogen is more than just a 'sex hormone': novel sites for estrogen action in the hippocampus and cerebral cortex. Front Neuroendocrinol 2000;21:95-101.

39 Woolley CS: Electrophysiolocgical and celluar effects oft estrogen and neuronal function. Crit Review Neurobiol1999;13:1-20.

40 Riecher-Rösler A: Östrogene und Psychopharmaka. Östrogene in der Psychiatrie - Psychopharmaka in der Gynäkologie? Ars Medici 2008;25/26:1118-21.

41 Rao ML, Kölsch H: Einfluss von Östradiol-17 $\beta$ auf die Hirnentwicklung und seine Eigenschaften als Neuroprotektivum. J Neurol Neurochir Psychiatr 2002;3:34-9.

42 Maurer K, Häfner H: Die Östrogenhypothese der Schizophrenie - Übersicht und aktueller Stand der Forschung. J Neurol Neurochir Psychiatr 2002; 3:26-31.

43 McEwen BS: Estrogen effects on the brain: much more than sex. Karger Gazette Hormones 2005; $66: 1-9$.

44 Bonuccelli U, Melis GB, Paoletti AM, Fioretti P, Murri L, Muratorio A: Unbalanced progesterone and estradiol secretion in catamenial epilepsy. Epilepsy Res 1989;3:100-6.
5 Belfort MA, Saade GR, Snabes M, Dunn R, Moise KJ Jr, Cruz A, Young R: Hormonal status effects the reactivity of cerebral vasculature. Am J Obstet Gynecol 1995;172:1273-8.

46 Bishop J, Simpkins JW: Role of estrogens in peripheral and cerebral glucose utilization. Rev Neurosci 1992;3:121-37.

47 Resnick SM, Maki PM, Rapp SR, Espeland MA, Brunner R, Coker LH, Granek IA, Hogan P, Ockene JK, Shumaker SA: Effects of combination estrogen plus progestin hormone treatment on cognition and affect. J Clin Endocrinol Metable 2006;91:1802-10.

48 Schiff R, Bulpitt CJ, Wesnes KA, Rajkumar C Short-term transdermal estradiol therapy, cognition and depressive symptoms in healthy older women. A randomised placebo controlled pilot cross-over study. Psychoneuroendocrinology 2005;30:309-15.

49 Sherwin BB, Henry JF: Brain aging modulates the neuroprotective effects of estrogen on selective aspects of cognition in women: a critical review. Front Neuroendocrinol 2008;29:88-113.

50 Jenkins V, Shilling V, Fallowfield L, Howell A, Hutton S: Does hormone therapy for the treatment of breast cancer have a detrimental effect on memory and cognition? A pilot study. Psychooncology 2004;13:61-6.

51 Bender CM, Sereika SM, Brufsky AM, Ryan CM, Vogel VG, Rastogi P, Cohen SM, Casillo FE, Berga SL: Memory impairments with adjuvant anastrozole versus tamoxifen in women with earlystage breast cancer. Menopause 2007;14:995-8.

52 Palmer JL, Trotter T, Joy AA, Carlson LE: Cognitive effects of tamoxifen in pre-menopausal women with breast cancer compared to healthy controls. J Cancer Surviv 2008;2:275-82.

53 Collins B, Mackenzie J, Stewart A, Bielajew C, Verma S: Cognitive effects of hormonal therapy in early stage breast cancer patients: a prospective study. Psychooncology 2008; Epub ahead of print.

54 Ernst T, Chang L, Cooray D, Salvador C, Jovicich J, Walot I, Boone K, Chlebowski R: The effects of tamoxifen and estrogen on brain metabolism in elderly women. J Natl Cancer Inst 2002;17;94:592-7.

55 Chang L, Ernst T, Poland RE, Jenden DJ: In vivo proton magnetic resonance spectroscopy of the normal aging human brain. Life Sci 1996;58:2049-56.

56 Paganini-Hill A, Clark LJ: Preliminary assessment of cognitive function in breast cancer patients treated with tamoxifen. Breast Cancer Res Treat 2000; $64: 165-76$

57 Hermelink K, Henschel V, Untch M, Bauerfeind I, Lux MP, Munzel K: Short-term effects of treatment-induced hormonal changes on cognitive function in breast cancer patients: results of a multicenter, prospective, longitudinal study. Cancer 2008;1;113:2431-9.

58 Jenkins VA, Ambroisine LM, Atkins L, Cuzick J, Howell A, Fallowfield LJ: Effects of anastrozole on cognitive performance in postmenopausal women a randomised, double-blind chemoprevention trial (IBIS II). Lancet Oncol 2008;9:953-61.

59 Hadji P, Ziller V, Holzhauer W, Ziller M, Kalder $\mathrm{M}$, Wagner $\mathrm{U}$ : Compliance with tamoxifen and arimidex in the adjuvant treatment of women with breast cancer. Breast Cancer Res Treat 2007; 106:146-50.

Berndt/Leplow/Kantelhardt/Thomssen 